Retos, $n^{\circ} 13$, vol.VII, 2017

\title{
La comunicación de marketing en la empresa de distribución española Mercadona
}

\section{Marketing communication in spanish retailer company Mercadona}

\author{
Dr. Pedro Pablo Marín Dueñas \\ Universidad de Cádiz \\ pablo.marin@uca.es. \\ orcid.org/0000-0001-8692-1174 \\ Jesús Lozano Fernández \\ Universidad de Cádiz \\ gmuratalla@itvallemorelia.edu.mx \\ jesusfpo@gmail.com \\ orcid.org/0000-0002-5779-0598
}

\begin{abstract}
Resumen
Esta investigación profundiza en la manera en que la empresa de distribución española Mercadona, una de las más importantes del país y con mayor crecimiento en los últimos años, desarrolla su comunicación comercial o de Marketing. Se analizará la comunicación externa que la empresa realiza y se prestará además especial atención al uso que hace la organización de Internet y de las principales redes sociales, con el objetivo de conocer las herramientas de comunicación que implementa en su estrategia comunicativa. Para ello se ha desarrollado una metodología mixta cuali-cuantitativa, basada en las técnicas de la observación y el análisis de contenido, de cuya aplicación se desprende que Mercadona utiliza, preferentemente, herramientas de comunicación de las denominadas No Convencionales o No Masivas, sin hacer uso de las más tradicionales, como puede ser la publicidad en televisión, prensa o radio. Por otro lado, está presente en las principales redes sociales digitales, haciendo un uso eficiente de ellas, aunque este uso está más enfocado a comunicar su identidad corporativa que en dar a conocer sus productos. De los resultados se desprende, a modo de conclusión, que la empresa de distribución Mercadona está más centrada en comunicar desde una perspectiva de corporate que comercial.
\end{abstract}

\begin{abstract}
This research analyzes the marketing communication of Mercadona, a spanish retaliler company. Is analyzed the external communication of the company, paying special attention to Internet and social networks. The aim of the research is to understand the main communication tools used in its communication strategy. The research methodology used has been the observation and analysis of content. The main results determine a preferential use of the communication tools denominated nonconventional or below the line. Mercadona is present in the main social media and makes an efficient use of them, although Mercadona uses these tools from a more corporate than commercial perspective.
\end{abstract}

\section{Palabras clave | keywords}

Distribución, marketing, comunicación comercial, redes sociales, internet, herramientas. Retailer, marketing, commercial communication, social media, internet, tools. 


\section{Introducción}

Es habitual que las grandes empresas de distribución bombardeen constantemente a los consumidores con anuncios, folletos, catálogos, cuñas de radio o inserciones publicitarias en distintas webs. En cambio, la empresa de distribución española Mercadona, líder del sector en España, ya en 1993, coincidiendo con la primera gran expansión de la compañía fuera de la comunidad valenciana, invirtió sus últimas pesetas en publicidad en televisión, con un anuncio en Televisión Española que comenzaba con la frase "nueve de cada diez mujeres dicen sí a SPB (Siempre Precios Bajos)". Desde entonces, la empresa no ha vuelto a utilizar la publicidad convencional; es decir, no invierte en anuncios de la propia empresa ni en folletos con ofertas de productos para distribuirlos en los buzones, en los periódicos o en sus propios puntos de venta, mientras que sí parece preocuparse en mantener y en mejorar su reputación, en dialogar con el cliente o en ponerse totalmente a su servicio. En definitiva, en hacer las cosas de una manera no tan visible y ruidosa como el resto, con una prudencia que suele llamar mucho la atención de los estudiosos de la comunicación.

Muchos son los que afirman que a Mercadona no le hace falta hacer publicidad o promocionarse. Nada más lejos de la realidad. Todo lo que ha conseguido la empresa valenciana no se consigue por casualidad, siendo planificado y estudiado al detalle. Mercadona ha decido publicitarse y promocionarse, al igual que todas, pero de una manera distinta a lo considerado como lo habitual en estos casos, de una manera silenciosa a la vez que eficaz.

A lo largo del presente trabajo se intentará profundizar en la manera en la que Mercadona desarrolla su comunicación de Marketing, en el qué hace, cómo lo hace, en el quién lo hace y en el por qué lo hace. Para ello se analizará la comunicación externa de la empresa y se prestará, además, especial atención a Internet y a sus redes sociales, entendiendo que, desde hace unos años, desempeñan un papel fundamental dentro de las estrategias de comunicación de las grandes empresas. Los análisis y las conclusiones que se obtengan proporcionarán un acercamiento al denominado «fenómeno Mercadona», basado en su modelo de gestión de la calidad total que implica una forma novedosa y poco habitual de gestionar la comunicación en una empresa tan importante, prestigiosa y extendida. 


\section{Las principales empresas de distribución alimentaria en España. La empresa de supermercados Mercadona}

De acuerdo con la información de Actualidad Económica, la cuota de mercado de Mercadona en el primer semestre del 2012 en envasados y frescos era del $25,3 \%$, frente al $24,8 \%$ que obtuvo en los seis primeros meses de 2013. Según los expertos del sector, durante el primer semestre del año se ha mantenido la tendencia deflacionista en productos de consumo alimentario. Las tiendas con precios bajos siguen acaparando cuota de mercado y se han consolidado durante 2013 como el canal favorito para hacer la compra en el ámbito del Gran Consumo. Este es uno de los datos más relevantes que se desprende del informe «Worldpanel Distribución 2014» que elabora la consultora Kantar Worldpanel y con el que se pretenden analizar las tendencias en el sector de la distribución. Mientras que los hipermercados y supermercados normales mantienen unas cuotas de mercado que rondan en valor el $14 \%$ y el $21 \%$ respectivamente, las tiendas con precios bajos han aumentado su cuota de mercado del 32,3\% al 34\% en tan sólo un año, lo que se traduce en una ventaja de más de tres puntos con respecto a las tiendas especializadas y de ultramarinos, que rondan el 30,7\%.

Otro de los datos relevantes que se extraen del informe de Kantar Worldpanel es que Mercadona, Dia y Lidl son las únicas firmas de gran distribución que han aumentado su cuota de mercado de entre la lista de las diez que más venden en España. El resto de componentes de este ranking de la gran distribución ha logrado mantener su presencia entre los diez primeros puestos. Así, Mercadona ya concentra el 22,3\% del gasto en productos de gran consumo (en 2012 concentraba el 20\%), mientras que DIA, con un $7,8 \%$ (7,7\% en 2012), se coloca por encima de Carrefour Híper, que mantiene el 7,7\% que ya tenía en 2012. Al gigante francés le siguen muy de cerca Eroski Súper $(3,3 \%)$, Lidl $(3 \%)$ y Alcampo $(2,9)$.

En 2015, Mercadona continúa liderando el panorama de la distribución con un 22,9\% del mercado, creciendo 2 décimas $(22,7 \%$ en el mismo periodo de 2014), al igual que Carrefour, que pasa del 8,3\% al 8,5\%. Eroski retrocede una décima hasta el 6,3\% de cuota $(6,4 \%$ en 2014) tras la venta de algunas de sus tiendas y el grupo Alcampo mantiene el 3,8\%, señala este informe con datos acumulados hasta el tercer trimestre de 2015.

Mercadona es una de las compañías más importantes de España de distribución, integrada dentro del segmento de los supermercados. 
Todo ello ha sido posible a través de un rápido crecimiento en un breve periodo de tiempo. Mercadona S. A. nace en 1977, en el seno del grupo Cárnicas Roig con el propósito de extender la comercialización de carnes y expandirse al negocio de ultramarinos. Su nombre proviene de la fusión de las palabras en valenciano "Mercat" (Mercado) y "Dona" (Mujer). Cuatro años después al nacimiento de la compañía, Juan Roig, uno de los hijos del fundador, adquiere la empresa, que en ese momento constaba de ocho establecimientos de ultramarinos en Valencia transformándolos en una pequeña cadena de supermercados que, que poco a poco, se desplegaría por la Comunidad Valenciana y, posteriormente por el resto de España

En la actualidad esta empresa de distribución, con capital 100\% español, está presente en 46 provincias con unos 1450 supermercados que, con una media de entre 1300 y 1500 metros cuadrados de sala de ventas, representan una cuota de mercado sobre la superficie total de alimentación en España del 22,3\% (Kantar World Panel, 2014) y contribuyen al dinamismo del entorno comercial en el que están ubicadas.

Actualmente más de 74000 personas, todas ellas con contratos fijos, desarrollan su vida profesional en la compañía con un mismo objetivo: satisfacer las necesidades en alimentación, limpieza del hogar, higiene y comida para animales domésticos, de los más de 4,8 millones de hogares que realizan diariamente su compra en Mercadona.

Los supermercados Mercadona, responden a un modelo de comercio urbano de proximidad, y mantienen un surtido en alimentación, droguería, perfumería y complementos que se caracteriza por potenciar la presencia de sus propias marcas blancas -también llamadas contramarcas- $y$ reducir la oferta de aquellas marcas externas que no mantengan un mínimo de rotación (Memoria Anual de Mercadona, 2014).

\section{La comunicación comercial y sus principales herramientas}

Se puede entender la comunicación comercial empresarial como aquella comunicación que establecen las empresas para relacionarse con los consumidores o personas que influyen en el proceso de compra. Su objetivo básico es lograr el consumo/uso de los productos y servicios que la empresa ofrece al mercado.

De acuerdo con Mazo-del-Castillo (1994) uno de los modelos básicos en los que se estructura la Comunicación Empresarial es el denominado "de comercialización o de marketing", que considera la 
Comunicación como un conjunto de técnicas cuyo principal objetivo está condicionado a los intereses comerciales. La Comunicación sólo tiene sentido para una empresa si ello implica lograr los objetivos de marketing (de producto o de marca).

Tradicionalmente la Comunicación ha estado unida a las actividades de marketing de las empresas (se centraba en los productos), buscando la mejor manera de comercializarlos. Prácticamente, hasta finales del siglo XX, la Comunicación en las empresas se limitaba a hacer publicidad o desarrollar alguna técnica que promocionara el producto (Carrillo y Castillo, 2007).

Este hecho responde a que habitualmente en las empresas se priorizan las políticas más tangibles (finanzas, producción, marketing). La gestión empresarial, por tanto, se preocupa mucho más por la Comunicación Comercial o de producto que por otras. En la actualidad, en mercados altamente competitivos, en los que los consumidores tienen una amplia oferta de productos y marcas para satisfacer una misma necesidad, no basta con ofrecer un producto de calidad excepcional, sino que, como señalan Reinares y Calvo (1999, p. 1) "es necesario comunicarse con los clientes y darles a conocer la oferta de la empresa, ya que si no la conocen difícilmente podrán comprarlos”.

En esta línea, Carrillo et al. (2005) señala que en un mercado en el que concurren multitud de productos y servicios con características muy similares, la diferenciación viene, en muchas ocasiones, de desarrollar una eficiente comunicación comercial. Así, la percepción que se tiene de cada marca hace que los consumidores se decanten por un producto o un servicio determinado que, probablemente, compita en igualdad de precio y características con otros bienes. Resulta obvia, por tanto, la relevancia de una buena estrategia de comunicación para los productos y, a fin de cuentas, también para la empresa (Carrillo et al., 2005, p. 29).

Ante la ya mencionada semejanza que existe entre los productos y la dificultad para diferenciar las mismas basadas en valores tangibles, la denominada Comunicación Comercial está ligada, en la actualidad, no sólo al producto sino también a la marca. Como apuntan Carrillo et al. (2005, p. 33):

(...) la marca se ha convertido en un valioso recurso cuya gestión depende directamente de la alta dirección de las organizaciones, con la ayuda del departamento de comunicación o cualquier otra denominación que se dé a los encargados de gestionar, sobre todo, la comunicación de la empresa. 
Gestionar la marca se convierte, por tanto, en una necesidad creciente para las empresas porque también los consumidores perciben ciertos valores y beneficios aportados por las mismas (Delgado, 2003).

El eje tradicional de la actividad de comunicación en las empresas, para informar a los consumidores sobre sus marcas y sus productos o servicios ha sido, prioritariamente, la publicidad, pero no es la única herramienta. También se utilizan otras actividades convencionales como el marketing directo, la Comunicación en el punto de venta, el merchandising, las promociones, el patrocinio, las ventas personales, etc. Los medios y soportes que utiliza la Comunicación Comercial o de Marketing son, fundamentalmente:

1. Comunicación directa y venta personal. Se trata de las acciones de comunicación que realiza la fuerza de ventas de la empresa de cara a sus clientes, normalmente este tipo de comunicación suele ser directa aunque sea a través de internet, correo, teléfono o cara a cara.

2. Publicidad en diarios. Tanto los de información general, como los gratuitos, los deportivos, etc.

3. Publicidad en dominicales.

4. Publicidad en Revistas. Tanto de información general, como especializadas en decoración, femeninas, masculinas, moda, corazón, deportes, etc.

5. Publicidad en Radio.

6. Publicidad en Cine.

7. Publicidad en Televisión. Incluye televisiones nacionales, autonómicas, canales temáticos, televisiones locales, etc.

8. Publicidad en Exterior. Incluye cabinas de teléfono, transporte, marquesinas monopostes, luminosos, lonas, vallas, carteles, banderolas, señales aéreas, etc.

9. Publicidad en Internet ( $\mathrm{pc}$ y móvil). Incluye enlaces patrocinados y formatos gráficos.

10. Publicidad, displays y animaciones en el punto de venta.

11. Merchandising, rotulación, directorios.

12. Marketing promocional y promoción de ventas.

13. Marketing relacional.

14. Marketing directo.

15. Buzoneo y folletos.

16. Marketing telefónico.

17. Marketing móvil (excluido internet).

18. Ferias y exposiciones. 
19. Actos de patrocinio deportivo.

20. Publicaciones empresariales.

La herramienta a utilizar vendrá determinada por el tipo de producto o servicio, los recursos disponibles de la empresa, la naturaleza del mercado, las etapas del proceso de compra, el ciclo de vida del producto, si son productos de gran consumo o productos industriales, etc. Y también por el tipo de estrategia empresarial y comunicacional. Las empresas, a través de la implementación de estas herramientas, persiguen una serie de objetivos entre los que se pueden destacar, principalmente: la creación de imagen de marca, la diferenciación de producto, el posicionamiento, el cambio de actitudes, generar confianza hacia una marca, comunicar ventajas, diferenciar la marca, presentar nuevos productos, entre otros (Soler, 1993), pero, sobre todo, incrementar las ventas y mejorar los resultados de la organización.

En cualquier caso, tanto la definición de los objetivos como la elección de los medios debe estar apoyada en una gestión estratégica de la Comunicación Comercial que, planificada previamente, permita a la organización establecer relaciones lo más sólidas posibles con sus consumidores, reportando los mayores beneficios posibles, en todos los sentidos, para la organización.

\section{Material y métodos}

\section{Objetivos de la investigación}

La presente investigación tiene como eje a la empresa de distribución alimentaria española Mercadona S.A y su comunicación de Marketing. Partiendo de este objeto de estudio se han planteado una serie de objetivos básicos que, a su vez, se componen de una serie de objetivos de carácter secundario que complementan y dan cuerpo a los primeros. Como objetivo principal se pretende conocer y analizar las herramientas de comunicación de Marketing que utiliza la empresa Mercadona. Para ello se procederá a analizar la comunicación que realiza esta empresa de distribución alimentaria a través de Internet, teniendo en consideración tanto la presencia y uso que hace de sus redes sociales como de su portal web institucional. 


\section{Metodología y diseño de la investigación}

\section{Observación}

A lo largo de este trabajo, la observación se ha planteado como un proceso sistemático, consciente, planificado y objetivo. Gracias a esta técnica se obtiene una información de carácter primario sobre el objeto de estudio, así como una muestra del proceder y conducta de las personas y grupos que se pretenden estudiar. Para el desarrollo de esta técnica metodológica se ha elaborado una ficha de análisis (Tabla 1) a partir de la clasificación realizada por el organismo Infoadex, que distingue, a grandes rasgos, entre medios de comunicación convencionales y medios de comunicación no convencionales.

Tabla 1. Ficha de análisis de medios para el estudio de la comunicación comercial

\begin{tabular}{|l|l|}
\hline \multicolumn{1}{|c|}{ MEDIOS CONVENC. } & UTILIZACIÓN \\
\hline Cine & \\
\hline Diarios & \\
\hline Dominicales & \\
\hline Exterior & \\
\hline Radio & \\
\hline Internet & \\
\hline Revistas prensa & \\
\hline Televisión & \\
\hline \multicolumn{1}{|c|}{ MEDIOS NO CONVENC. } & \\
\hline Patrocinios & \\
\hline Mecenazgo & \\
\hline MK Social / RSC & \\
\hline Patrocinio Deportivo & \\
\hline Animación Pto.Venta & \\
\hline Anuarios & \\
\hline Guías y Directorios & \\
\hline Buzoneo / Folletos & \\
\hline Ferias / Exposiciones & \\
\hline Juegos Promocionales & \\
\hline
\end{tabular}




\begin{tabular}{|l|l|}
\hline \multicolumn{1}{|c|}{ MEDIOS NO CONVENC. } & UTILIZACIÓN \\
\hline Mailing personalizado & \\
\hline MK Móvil & \\
\hline MK telefónico & \\
\hline PLV Merchandising & \\
\hline Señalización / Rótulos & \\
\hline Revistas / Memoria & \\
\hline Regalos publicitarios & \\
\hline Tarjeta de fidelización & \\
\hline
\end{tabular}

Una vez validada dicha plantilla de análisis, las observaciones presenciales de los puntos de venta se han llevado a cabo en las localidades de Puerto Real, Cádiz, El Puerto de Santa María y Chiclana de la Frontera, todos ellos de la provincia de Cádiz (España). En total se han visitado cinco centros. Tanto la observación de los puntos de venta como el registro de los datos se han realizado en el período de tiempo comprendido entre los meses de marzo de 2015 y julio de 2016.

\section{Análisis de contenido}

Se trata de una técnica utilizada para poder interpretar y obtener conclusiones sobre textos, imágenes $\mathrm{u}$ otras formas diferentes donde puedan existir toda clase de registros de datos, trascripción de entrevistas, discursos, protocolos de observación o documentos. Esta metodología se ha aplicado sobre dos soportes distintos: El análisis de páginas web, por un lado, y el de las redes sociales, por otro. Partiendo de esta consideración se han diseñado dos fichas de análisis de elaboración propia. La ficha que se aplicará al análisis de la web corporativa (tabla 2) está fundamentada teóricamente en el trabajo de Marín, Lasso de la Vega y Mier-Terán (2015). A partir de estos trabajos se han seleccionado una serie de variables que permiten medir la navegabilidad, la organización, la legibilidad y el proceso de compra online que ofrece la Web. Para cada una de estas variables se han determinado una serie de ítems y se ha medido la presencia o no de cada uno de ellos en la web institucional. 
Tabla 2. Ficha para el análisis de la web institucional de Mercadona

\begin{tabular}{|c|c|}
\hline NAVEG & PRESENCIA \\
\hline \multicolumn{2}{|l|}{ Mapa del sitio } \\
\hline \multicolumn{2}{|l|}{ URL fácil de recordar } \\
\hline \multicolumn{2}{|c|}{ Enlaces pag. Ppal desde todas las páginas } \\
\hline \multicolumn{2}{|l|}{ Página de ayuda } \\
\hline \multicolumn{2}{|l|}{ Posee buscador } \\
\hline \multicolumn{2}{|c|}{ Se informa de cómo solucionar los problemas } \\
\hline \multicolumn{2}{|c|}{ ORGANIZACIÓN } \\
\hline \multicolumn{2}{|l|}{ Ordenada de forma lógica } \\
\hline \multicolumn{2}{|c|}{ Títulos describen información que encabezan } \\
\hline \multicolumn{2}{|c|}{ LEGIBILIDAD } \\
\hline \multicolumn{2}{|l|}{ Tamaño de letra adecuado } \\
\hline \multicolumn{2}{|c|}{ Imágenes fondo ofrecen buen contraste } \\
\hline \multicolumn{2}{|l|}{ Lenguaje claro y conciso } \\
\hline \multicolumn{2}{|c|}{ PROCESO DE COMPRA } \\
\hline \multicolumn{2}{|l|}{ Fotos de productos } \\
\hline \multicolumn{2}{|l|}{ Descripción de los productos } \\
\hline \multicolumn{2}{|l|}{ Navegación sin compra } \\
\hline \multicolumn{2}{|l|}{ Compra mínima } \\
\hline \multicolumn{2}{|l|}{ Ofrece diversos métodos de pago } \\
\hline \multicolumn{2}{|l|}{ Atención al cliente } \\
\hline \multicolumn{2}{|l|}{ Sitio seguro } \\
\hline Tiempo de carga entre páginas & \\
\hline
\end{tabular}

Como base teórica para la realización del análisis de las distintas redes sociales se ha diseñado una segunda ficha de análisis (tabla 3) a partir del trabajo de Fondevila, Del Olmo y Bravo (2012). Se van a analizar, concretamente, el número medio de seguidores, la calidad de las imágenes, la periodicidad con la que se suben materiales, el tipo de 
contenidos y si permite o no el diálogo y la interacción con los clientes para cada una de las redes sociales en las que Mercadona tiene presencia.

Tabla 3. Ficha de análisis para el estudio de las redes sociales de Mercadona

\begin{tabular}{|l|l|l|l|l|l|l|} 
& $\begin{array}{c}N^{0} \text { medio } \\
\text { seguidores }\end{array}$ & $\begin{array}{c}\text { Calidad } \\
\text { imágenes } \\
\text { texto }\end{array}$ & $\begin{array}{c}\text { Fecha } \\
1^{\mathrm{a}} \\
\text { utilización }\end{array}$ & $\begin{array}{c}\text { Periodicidad } \\
\text { subida }\end{array}$ & $\begin{array}{c}\text { Tipo } \\
\text { contenidos }\end{array}$ & $\begin{array}{c}\text { Diálogo } \\
\text { cliente }\end{array}$ \\
\hline Facebook & & & & & & \\
\hline Twitter & & & & & & \\
\hline $\begin{array}{l}\text { Canal } \\
\text { Youtube }\end{array}$ & & & & & & \\
\hline Instagram & & & & & & \\
\hline Google + & & & & & & \\
\hline Linkedin & & & & & & \\
\hline $\begin{array}{l}\text { Blog } \\
\text { corporativo }\end{array}$ & & & & & & \\
\hline
\end{tabular}

El proceso de análisis se ha llevado a cabo entre los meses de junio y julio de 2016, aplicando dichas fichas de análisis a la web corporativa, así como a las principales redes sociales digitales.

\section{Análisis y resultados}

\section{Herramientas de comunicación}

Las herramientas que se han medido y analizado corresponden a la clasificación realizada por el organismo Infoadex, que distingue, a grandes rasgos, entre medios de comunicación convencionales y medios de comunicación no convencionales. Tal y como se puede observar en la ficha de análisis (tabla 4), en lo que respecta a los medios de comunicación denominados convencionales, se observa cómo Mercadona prescinde de la utilización de los dos principales y más populares como son la televisión y la radio, destacando la utilización del medio Internet. Además, la publicidad exterior, y más concretamente las vallas publicitarias señalizadoras, son utilizadas por Mercadona, empleando soportes de diversos tamaños según considere que la ubicación de su punto de venta pueda o no llevar a la confusión a los posibles clientes. Además de vallas o monopostes, suele utilizar marquesinas ubicadas en paradas de autobús urbano o tren siempre cercanas al punto de venta. 
Tabla 4. Resultados. Medios utilizados por Mercadona en su comunicación de Marketing

\begin{tabular}{|c|c|}
\hline MEDIOS CONVENC. & MERCADONA \\
\hline \multicolumn{2}{|l|}{ Cine } \\
\hline \multicolumn{2}{|l|}{ Diarios } \\
\hline \multicolumn{2}{|l|}{ Dominicales } \\
\hline Exterior & $x$ \\
\hline \multicolumn{2}{|l|}{ Radio } \\
\hline Internet & $x$ \\
\hline \multicolumn{2}{|l|}{ Revistas prensa } \\
\hline \multicolumn{2}{|l|}{ Televisión } \\
\hline MEDIOS NO CONVENC. & MERCADONA \\
\hline \multicolumn{2}{|l|}{ Patrocinios } \\
\hline Mecenazgo & $x$ \\
\hline MK Social / RSC & $x$ \\
\hline Patrocinio Deportivo & $x$ \\
\hline Animación Pto.Venta & $x$ \\
\hline \multicolumn{2}{|l|}{ Anuarios } \\
\hline \multicolumn{2}{|l|}{ Guías y Directorios } \\
\hline \multicolumn{2}{|l|}{ Buzoneo / Folletos } \\
\hline \multicolumn{2}{|l|}{ Ferias / Exposiciones } \\
\hline \multicolumn{2}{|l|}{ Juegos Promocionales } \\
\hline \multicolumn{2}{|l|}{ Mailing personalizado } \\
\hline \multicolumn{2}{|l|}{ MK Móvil } \\
\hline \multicolumn{2}{|l|}{ MK telefónico } \\
\hline PLV Merchandising & $x$ \\
\hline Señalización / Rótulos & $x$ \\
\hline Revistas / Memoria & $x$ \\
\hline \multicolumn{2}{|l|}{ Regalos publicitarios } \\
\hline Tarjeta de fidelización & $x$ \\
\hline
\end{tabular}


En lo referente a los medios no convencionales se puede observar cómo Mercadona utiliza un menor número de herramientas que el resto de empresas de distribución. Entre ellas resulta bastante significativo el desarrollo de acciones de mecenazgo. El nombre de la empresa no consta ni aparece en ninguno de estos patrocinios, cesiones o donaciones, utilizando en cambio el de alguna de sus fundaciones afines, como por ejemplo la fundación Trinidad Alfonso o el patrocinio que se hace al Club Baloncesto Valencia de la Liga ACB, a través de la aparición del eslogan «Cultura del Esfuerzo» en su camiseta, eslogan acuñado y frase siempre utilizada por el presidente de la compañía D. Juan Roig Alfonso. Mercadona no participa en ferias ni en exposiciones temáticas sobre alimentación. Tampoco utiliza juegos promocionales o de puntos que posteriormente se canjean por descuentos en la compra.

Es muy usual que las empresas de distribución alimentaria utilicen como herramienta el buzoneo. Las diferentes y variadas ofertas que van promoviendo suelen trasladarlas a la ciudadanía de esta forma, excepto Mercadona, que no lo suele emplear ni siquiera en la apertura de un nuevo punto de venta. También es habitual la utilización, por parte de las empresas del sector, de tarjetas de crédito o fidelización. Mercadona en este sentido la utiliza únicamente para financiar las compras y aplazar los pagos, pero no para ofrecer descuentos, promociones, entre otras.

\section{Análisis de la presencia y utilización de las redes sociales de Mercadona}

Como se puede observar en la tabla 5, Mercadona hace un uso bastante importante de las redes sociales digitales desde que en agosto de 2012 comenzara a utilizar Facebook y Twitter, mientras progresivamente fuera adhiriéndose a las principales y más populares redes sociales digitales. 
Tabla 5. Uso de los social media por parte de Mercadona

\begin{tabular}{|c|c|c|c|c|c|c|}
\hline 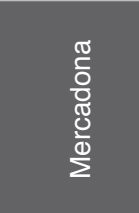 & 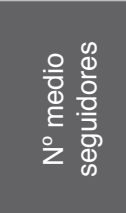 & 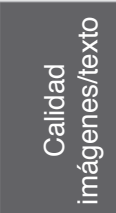 & 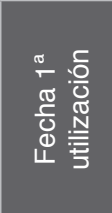 & 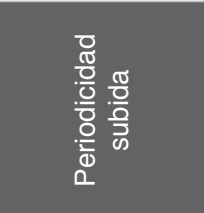 & 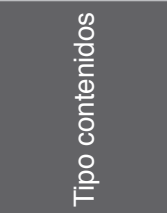 & 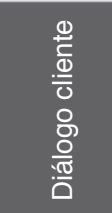 \\
\hline Facebook & 420.000 & $\begin{array}{l}\text { Muy } \\
\text { buena }\end{array}$ & ago-12 & $\begin{array}{l}1 \text { post diario } \\
\text { media }\end{array}$ & $\begin{array}{l}\text { Productos / } \\
\text { Advertencias }\end{array}$ & $\begin{array}{l}\text { Fluido y } \\
\text { buscado }\end{array}$ \\
\hline Twitter & 83.000 & $\begin{array}{l}\text { Muy } \\
\text { buena }\end{array}$ & ago-12 & $\begin{array}{l}\text { 1-3 mensajes } \\
\text { respuestas }\end{array}$ & $\begin{array}{l}\text { Productos } \\
\text { Diálogo }\end{array}$ & $\begin{array}{l}\text { Fluido y } \\
\text { buscado }\end{array}$ \\
\hline $\begin{array}{l}\text { Canal You- } \\
\text { tube }\end{array}$ & 2.000 & $\begin{array}{l}\text { Muy } \\
\text { buena }\end{array}$ & may-13 & 1 video mensual & $\begin{array}{l}\text { Productos } \\
\text { Proveedores }\end{array}$ & \\
\hline Instagram & 450 & $\begin{array}{l}\text { Muy } \\
\text { buena }\end{array}$ & mar-15 & $\begin{array}{l}\text { comienza a } \\
\text { utilizar }\end{array}$ & $\begin{array}{l}\text { Productos } \\
\text { Proveedores }\end{array}$ & \\
\hline Google + & 660 & $\begin{array}{l}\text { Muy } \\
\text { buena }\end{array}$ & may-13 & 1 subida diaria & $\begin{array}{l}\text { Productos } \\
\text { Proveedores }\end{array}$ & \\
\hline Linkedin & 23.900 & $\begin{array}{l}\text { no desa- } \\
\text { rrollado }\end{array}$ & & 0 & 0 & \\
\hline $\begin{array}{l}\text { Blog } \\
\text { corporativo }\end{array}$ & $\begin{array}{l}\text { canalmer- } \\
\text { cadona }\end{array}$ & $\begin{array}{l}\text { Muy } \\
\text { buena }\end{array}$ & & diaria & $\begin{array}{l}\text { Noticias } \\
\text { varias }\end{array}$ & \\
\hline
\end{tabular}

Es menester destacar la calidad de las imágenes, de los textos, así como del proceso de interacción con el cliente, que se evidencia continuo, profesional y sistemático. Mercadona no suele llenar los muros o los timelines de mensajes si no es preciso. De media suele publicar uno o dos posts diarios en Facebook, así como entre uno y tres mensajes en Twitter. Uno de los aspectos por los que Mercadona y su estrategia en redes destacan es por el hecho de que la interacción con el cliente es constante y profesional. El equipo de gestores de redes de Mercadona responde a todas las dudas, quejas y reclamaciones de los clientes de forma rápida y asertiva. La empresa también destaca y se diferencia del resto por la no utilización del «retuit». Todos los contenidos e imágenes que publica son de producción propia y elaboradas por su departamento. Asimismo se destaca la cada vez más constante utilización de otras redes sociales como Instagram o Google +.

\section{Análisis de la web institucional de Mercadona}

En lo que respecta a la web de Mercadona, se puede afirmar que se trata de una web con un diseño austero, no demasiado ornamentado gráficamente $y$, a la vez, muy navegable. Lo realmente interesante de esta web es la remisión al blog corporativo de la compañía (Canalmercadona), en 
el que se insertan a diario noticias, aclaraciones e incluso respuestas a los numerosos bulos que, sobre la empresa, circulan por las redes sociales.

Tal y como se desprende de los datos recogidos en la ficha de análisis (tabla 6), a primera vista no parece en absoluto la web de e-Commerce de una gran compañía líder en su sector. El diseño es obsoleto y bastante austero, propio de una web de principio de los años noventa. Si nos centramos en su plataforma de compra online, como en la mayoría de plataformas de estas características, es necesario registrarse para poder acceder a ella y proceder al pedido de productos dentro del surtido que se ofrece.

Tabla 6. Análisis de la web institucional de Mercadona

\begin{tabular}{|c|c|}
\hline \multicolumn{2}{|c|}{ NAVEGABILIDAD } \\
\hline Mapa del sitio & $x$ \\
\hline URL fácil de recordar & $x$ \\
\hline Enlaces pag. Ppal desde todas las páginas & 0 \\
\hline Página de ayuda & $\mathrm{O}$ \\
\hline Posee buscador & 0 \\
\hline Se informa de cómo solucionar los problemas & $\mathrm{O}$ \\
\hline \multicolumn{2}{|c|}{ ORGANIZACIÓN } \\
\hline Ordenada de forma lógica & $x$ \\
\hline Títulos describen información que encabezan & O \\
\hline \multicolumn{2}{|c|}{ LEGIBILIDAD } \\
\hline Tamaño de letra adecuado & O \\
\hline Imágenes fondo ofrecen buen contraste & $x$ \\
\hline Lenguaje claro y conciso & $x$ \\
\hline \multicolumn{2}{|c|}{ PROCESO DE COMPRA } \\
\hline Fotos de productos & O \\
\hline Descripción de los productos & O \\
\hline Nevegación sin compra & $x$ \\
\hline Compra mínima & $x$ \\
\hline Ofrece diversos métodos de pago & $x$ \\
\hline Atención al cliente & $x$ \\
\hline Sitio seguro & $x$ \\
\hline Tiempo de carga entre páginas & O \\
\hline
\end{tabular}


Entre los aspectos negativos de la web de venta destaca la no existencia de productos destacados, ni de fotografías de productos, de ofertas o de descripciones detalladas de productos, excepto los de sus marcas o contramarcas que sí aparecen lo suficientemente detallados. En la plataforma de compra no existen ofertas más allá de un ítem del menú lateral identificado como bajada PVP. Los tipos de letra son de difícil lectura en la mayoría de las ocasiones, aspecto que en muchas ocasiones complica la decisión de compra. El carrito de la compra o compra virtual es una especie de ticket virtual que aparece en el lado derecho parecido a un cuadro de Excel y de difícil manejo e interpretación. No obstante, la web ofrece la posibilidad de crear listas de productos y guardarlas y tiene una buena tarifa de servicio a domicilio que ronda los 8 euros.

La plataforma web tiene pocas secciones o páginas de contenido. Es posible además acceder desde ella a contenidos relacionados con la tarjeta de fidelización de la empresa, a información corporativa sobre la misma o a ofertas de empleo publicadas por la propia empresa, aspecto este gestionado profesionalmente por la web infojobs.net.

Otro de los aspectos en los que destaca la web es en la posibilidad de acceder a ella en bastantes idiomas. Aparte de poder hacerlo en castellano, en catalán o en euskera, es posible hacerlo en valenciano, en gallego, en inglés o en alemán. En lo referente al ranking global de visitas de esta web, se puede afirmar que se encuentra bien posicionada en España con una media de permanencia en la página por visita de 4,17 minutos, una visita de 4,1 páginas o secciones por visitante, ocupando el puesto 927 del ranking español.

A pesar de no ser una web sencilla y práctica para el cliente, la posición que ocupa en el ranking es bastante buena, quizá obtenida gracias a la popularidad de la empresa en lo referente a la venta directa y a la calidad de las marcas o contramarcas que comercializa en sus puntos de venta físicos.

\section{Discusión y conclusiones}

La diferencia de Mercadona con sus competidores directos es que ésta no usa la comunicación comercial de una manera convencional. Su idea no es llegar a las grandes masas a través de la comunicación comercial. De esta manera se colige que la empresa pretende humanizar la marca, llegar al cliente de la forma en la que una tienda típica de barrio lo ha hecho hasta ahora: con productos de calidad, proximidad al domi- 
cilio, y que el vendedor sea prescriptor de marcas, cercano y amable. De esta forma, Mercadona se centra y busca lo que se denomina comunicación corporativa.

En lo que respecta a las herramientas de comunicación que utiliza Mercadona S.A se puede determinar que, fundamentalmente, utiliza herramientas de comunicación de las denominadas No Convencionales o No Masivas. Mercadona sí está presente en las principales redes sociales digitales y hace un uso eficiente de ellas.

Entre las principales características del uso que hace de las redes sociales se destaca la calidad de las imágenes, los textos así como el proceso de interacción con el cliente, que, en todo momento, es continuo, profesional y sistemático. Su estrategia se basa en la comunicación corporativa más que en la comercial. Recalcar el hecho de que las temáticas más usuales en redes se centran en promocionar sus marcas propias, los procesos de elaboración, las denominaciones de origen de sus productos o la contribución de la empresa a la mejora del medioambiente y la contribución de la misma con fines de índole social.

Por su parte, la web de Mercadona es una interfaz sencilla y austera en lo referente a ilustraciones, ornamentación, funcionalidad y contenido. Al igual que en su estrategia en redes sociales, en la web se centran fundamentalmente en la empresa, en su contribución a la sociedad y en la importancia dentro del sector en España de ésta. En lo que respecta a la plataforma de compra online, también ha de destacarse su sencillez estética y su dificultad de uso. Los precios del servicio de entrega a domicilio de compras realizadas a través de la web sí son competitivos con respecto al resto. La falta de actualización y de mejoras en la web denotan el hecho de que Mercadona no apuesta mucho por este tipo de venta y enfocándose más hacia la venta directa, presencial o física.

A modo de conclusión, Mercadona se diferencia de sus principales competidores por el hecho de no utilizar, preferentemente, la comunicación comercial y sí utilizar de una forma más frecuente la comunicación corporativa, gestionando fundamentalmente herramientas de las denominadas no convencionales o no masivas. Mientras sus competidores se afanan en dar a conocer sus precios, sus ofertas, sus promociones, sus descuentos y sus productos, los datos observados y recogidos en este estudio nos indican que Mercadona prefiere que su imagen, sus productos propios y su forma de hacer las cosas llegue al público a través del 
cara a cara con el cliente para que, de esta forma, la compra se convierta en una experiencia placentera.

\section{Referencias}

Carrillo, M.V. y Castillo, A. (2007). El desarrollo de las estrategias de comunicación y de imagen en las PYMES. El caso de Extremadura. Fisec Estrategias, 6(7), 3-22.

Carrillo, M. V., Castillo, A., y Gómez, L. (2005). Imagen y comunicación en las PYMES. Madrid: Ed. Fragua.

Delgado, E. (2003). Controversia conceptual sobre el capital de marca: propuesta de un marco teórico de análisis. Revista Europea de Dirección y Economía de la Empresa, (12), 7-24.

Fondevila, J.F., Del Olmo, J.L. y Bravo, V. (2012). Presencia y reputación digital en "social media": comparativa en el sector de la moda. Fonseca, Journal of Communication, (5), 92-116.

Infoadex S.A. (2014). Resumen estudio inversión publicitaria en España 2014. (https:// goo.gl/njAg6J)

Kantar (s.f). Kantar Wordpanel Alimentación. (https://goo.gl/P06PB4)

Marín, P.P., Lasso de la Vega, C. y Mier-Terán, J.J. (2015). La interactividad de las webs en las pequeñas y medianas empresas. Opción, 31(3), 735-750.

Mazo del Castillo, J. M. (1994). Estructuras de la comunicación por objetivos: estructuras publicitarias y de Relaciones Públicas. Barcelona: Ariel.

Mercadona S.A. (2014). Memoria Anual 2014. (https://goo.gl/pGnTZP).

Reinares, P. y Calvo, S (1999). Gestión de la comunicación comercial. Madrid: McGraw Hill. 